\title{
Aprendizagem de língua estrangeira e argumentação em sala de aula: a perspectiva dialógica e discursiva em foco
}

\author{
Patrícia Falasca*
}

\section{Resumo}

A argumentação, inserida em uma proposta dialógica e discursiva de base bakhtinana de compreensão da linguagem, é concebida, neste trabalho, como uma forma privilegiada de construção de conhecimento. Nosso principal objetivo é discutir de que forma atividades de cunho argumentativo podem contribuir para a aprendizagem de línguas estrangeiras por alunos adultos. Resultados advindos de análises preliminares demonstram que o ato de engajar-se em argumentação e a dinâmica criada na sala de aula por tais atividades levam o aluno a posicionar-se enquanto sujeito na nova língua, enquanto, juntamente com os colegas, negocia significados e repensa seus pontos de vista.

Palavras-chave: Argumentação; Aprendizagem de língua estrangeira.

\begin{abstract}
The argumentation, in a bakhtinian dialogical and discursive perspective of language, is conceived in this paper as a privileged way of knowledge building. Our main goal in this research is to discuss in which way argumentative activities can contribute to the foreign language learning process of adult students. Early results show that the engaging in argumentation and the dynamic these activities bring to classroom enables the students to posit themselves as subjects in the new language as they negotiate meaning with the group and rethink their point of views.
\end{abstract}

Key-words: Argumentation; Foreign language learning.

\section{Introdução}

Como forma de compreender os processos pelos quais os alunos adultos de línguas estrangeiras passam ao lançarem-se na tarefa de aprender uma nova língua, este trabalho discute os impactos trazidos por atividades de cunho argumentativo para os aprendizes, uma vez que defendemos que tais atividades podem ser de grande ajuda para a entrada do aluno na língua-alvo.

\footnotetext{
"Doutoranda na UNESP- Universidade Estadual Paulista "Júlio de Mesquita Filho", Faculdade de Ciências e Letras - campus de Araraquara; SP - Brasil. E-mail: patricia.falasca@ gmail.com 
Dessa forma, levantaremos neste artigo, inicialmente, as bases teóricas que nos ajudam a refletir sobre tais processos. Nesse contexto, faz-se de extrema importância considerar as contribuições do Círculo de Bakhtin (BAKHTIN, 2006; BAKHTIN/VOLOSHINOV, 1997; BAKHTIN, 1981; BAKHTIN/VOLOSHINOV, 1976) para as discussões sobre língua, linguagem, interação - adotadas por nós neste trabalho -, assim como seus desdobramentos a serem pensados na área de Aquisição/aprendizagem de línguas estrangeiras.

A partir de tais considerações, apresentamos a concepção de argumentação que permeia o estudo, baseando-nos nos trabalhos de Leitão (2011; 2008; 2007a; 2007b; 2003), do grupo NupArg ${ }^{1}$ e seus esforços para estudar questões da argumentação aplicada ao ensino (inicialmente, das disciplinas do currículo escolar, tais como geografia, história, etc., mas também pensadas em contextos universitários - como no curso superior de Psicologia da UFPE). É apenas tomando a argumentação como uma atividade privilegiada de construção do saber (LEITÃO, 2011; 2008; 2007a; 2007b; 2003) que podemos, então, desenvolver hipóteses sobre seus possíveis impactos na aprendizagem de línguas, proposta central desta pesquisa.

Como forma de discutir tais impactos e de compreender a importância da abordagem dialógico-discursiva nesse contexto, trazemos, por fim, uma breve análise de um trecho que compõe nosso estudo piloto, realizado com a participação de alunos universitários do curso de Letras, aprendizes de alemão como língua estrangeira. Tal análise abre possibilidades para as primeiras conclusões sobre as hipóteses lançadas pela pesquisa e leva também ao desenvolvimento de novas propostas de trabalho na área de ensino-aprendizagem de línguas.

\section{A linguagem e a perspectiva bakhtiniana}

Compreender a linguagem dentro da perspectiva proposta pelo chamado Círculo de Bakhtin tem sido o esforço de inúmeros estudiosos da linguagem e da literatura ao redor do mundo. Neste trabalho, trazemos uma breve discussão de algumas das ideias presentes nas obras do $\mathrm{Círculo}^{2}$, de forma a promover um diálogo com nossa proposta

\footnotetext{
${ }^{1}$ Núcleo de Pesquisa da Argumentação, UFPE. Coordenado pela Profa. Dra. Selma Leitão.

${ }^{2}$ Apesar de termos ciência das discussões que envolvem questões de autoria das obras publicadas em nome de Bakhtin e de outros membros do Círculo, não nos posicionamos, neste trabalho, a esse respeito. As citações aparecem, aqui, da forma como nos chegaram pelas edições por nós utilizadas.

Revista Leitura V.1 no 55 - jan/jun 2015 - Número temático: Estudos em perspectivas dialógicas. Aprendizagem de língua estrangeira e argumentação em sala de aula: a perspectiva dialógica e discursiva em foco. Patrícia Falasca - p. $23-40$.
} 
central: compreender o papel da argumentação nos processos de aprendizagem de línguas estrangeiras.

Para adentrar as ideias bakhtinianas, pontos centrais do que foi desenvolvido pelos pensadores do Círculo giram em torno da questão da interação verbal, do dialogismo, do discurso e da relação entre o eu e o outro. Naturalmente, atreladas a esses pontos, há ainda inúmeras outras contribuições do Círculo tanto para os estudos em Literatura, quanto para a Linguística - sem contar as demais áreas que estão, nos últimos anos, fazendo uso de tais ideias. Restringiremos nosso olhar, no entanto, para compreender de que forma as propostas bakhtinianas relacionam-se com a argumentação - ou, mais especificamente, de que forma é possível, a partir de tais ideias, desenvolver estudos voltados para questões de argumentação.

Ao propor uma forma de compreender a linguagem, Bakhtin/Voloshinov (1997) a definem como algo apenas possível se pensada juntamente com um conjunto de sujeitos socialmente organizados, capazes de gerar, em cada signo, um significado que lhe seja interindividual. Assim, a linguagem é compreendida como ideológica, uma vez que seu caráter social faz-se base de sua existência. É somente adquirindo um valor social que se adentra o domínio da ideologia. Dessa forma, nas palavras do próprio Bakhtin:

Todo signo, como sabemos, resulta de um consenso entre indivíduos socialmente organizados no decorrer de um processo de interação. Razão pela qual as formas do signo são condicionadas tanto pela organização social de tais indivíduos como pelas condições em que a interação acontece. (BAKHTIN/VOLOSHINOV, 1997 p. 44) (grifo do autor).

Assim, a linguagem é, nesse contexto, necessariamente marcada pelo "horizonte social de uma época e de um grupo social determinados" (1997, p.44) (grifo do autor), adquirindo uma dinamicidade ligada ao contexto sociocultural do qual participa. Sendo assim, a interação verbal faz-se a realidade fundamental da língua (MOLON; VIANNA, 2012).

Nessa perspectiva, é também na e pela linguagem que os indivíduos se tornam sujeitos no mundo, ao adentrar os discursos da sociedade na qual se encontram. E isso apenas ocorre quando há o mergulho no recorte do mundo feito por sua língua materna, permitindo o despertar de sua consciência enquanto sujeitos: 
[...] Os indivíduos não recebem a língua pronta para ser usada; eles penetram na corrente da comunicação verbal; ou melhor, somente quando mergulham nessa corrente é que sua consciência desperta e começa a operar. [...] Os sujeitos não "adquirem" sua língua materna; é nela e por meio dela que ocorre o primeiro despertar da consciência. (BAKHTIN/VOLOSHINOV, 1997, p.109-110)

Tendo isso em mente, compreendemos também a importância, dentro dessa perspectiva de estudos, da relação eu-outro. Essa relação é, para Bakhtin, constitutiva: o $e u$ se define em relação ao outro. Em concordância com o que apontam Molon e Vianna, em Bakhtin, "não se trata de instauração de lugar de fala (enunciação), mas sim da construção social da consciência e da linguagem pela intersubjetividade" (MOLON, VIANNA, 2012, p. 148). Permeada pela linguagem, essa relação instaura também, em última instância, as bases para a compreensão do dialogismo, um dos pontos centrais (senão o mais central) nas ideias de Bakhtin.

Considerando que a interação verbal se dá de maneira concreta, entre indivíduos reais e historicamente situados, estabelecendo uma relação eu-outro, constituída na e pela linguagem, que é ideológica por natureza, somos levados a pensar que também o enunciado estabelece interações entre si. Assim, cada enunciado concreto constitui-se como uma resposta a enunciados anteriormente realizados, suscitando, por sua vez, novas respostas. Cada discurso faz-se um elo na cadeia de comunicação verbal, a qual é infindável. Essa propriedade de os discursos estarem sempre em relação (ao mesmo tempo ser resposta e fazer emergir outras respostas) está na base da compreensão do dialogismo. É preciso notar que tal conceito é amplamente discutido e utilizado nas obras de Bakhtin e do Círculo, sendo, portanto, bastante complexo. Nosso intuito, neste trabalho, não é esgotar as possibilidades de compreensão do dialogismo, mas apenas compreender de que forma ele se relaciona à pesquisa aqui apresentada.

As propostas do Círculo de Bakhtin têm contribuído como aporte teórico para pesquisas em diversas áreas do conhecimento. No campo de Aquisição da Linguagem, reconhecemos os trabalhos de Frédéric François $(2006,1996,1989)$ e de Salazar-Orvig (2010a, 2010b; 1999) como os primeiros a trazer as ideias do Círculo para compreender questões relacionadas à entrada da criança em sua língua materna e os movimentos realizados por ela na e pela língua, considerando, como não poderia deixar de ser, a importância da palavra do outro e do diálogo para a formação de sua subjetividade. 
Seguindo as propostas de tais autores, reconhecemos também a importância do grupo de estudos GEALin ${ }^{3}$, que, com os trabalhos de diversos pesquisadores, busca discutir variadas facetas da aquisição de língua materna, assim como questões de bilinguismo e aprendizagem de línguas estrangeiras, pensadas a partir da perspectiva dialógico-discursiva de base bakhtiniana.

Com relação aos estudos em aprendizagem de línguas estrangeiras, os quais especialmente nos interessam neste trabalho, encontramos ainda um número reduzido de publicações que se preocupem em estabelecer um diálogo entre as ideias do Círculo com a área. Não obstante, podemos citar como exemplos de tais esforços os trabalhos de Hall (2013) e Marchenkova (2005). Também buscando estabelecer esse diálogo, há pesquisas dentro do grupo GEALin, já citado, voltadas para tais questões ${ }^{4}$. Incluímos também aqui os trabalhos de $\operatorname{Kramsch}(2009$, 1998, 1993), que, apesar de não considerar as ideias bakhtinianas como centrais em seus trabalhos, propõe, em determinados momentos, sua relevância nos estudos em ensino-aprendizagem de línguas estrangeiras.

Com isso, a questão que nos leva a pensar esses diálogos é, inicialmente, a seguinte: de que forma a argumentação poderia estar relacionada às questões de linguagem e dialogismo, considerados à luz da perspectiva bakhtiniana? E, mais especificamente, de que forma a argumentação, assim compreendida, poderia colaborar para a entrada do aluno na língua estrangeira?

\section{A argumentação no contexto escolar como forma de construção do conhecimento}

Ao tratar da argumentação na sala de aula, partimos de um entendimento de argumentação que passa pelas noções estabelecidas no Tratado da Argumentação: A Nova Retórica (2000), de Perelman e Olbrechts-Tyteca, especialmente em relação à consideração do auditório e de adesão do público, na visão dos autores. Tendo eles se preocupado especialmente em oferecer um arcabouço teórico aos estudos em argumentação, é também importante estabelecer a relação da noção de argumentação por nós adotada com aquela desenvolvida pela pragma-dialética, proposta por van

\footnotetext{
${ }^{3}$ Grupo de Estudos em Aquisição da Linguagem (FCLAr) - coordenado pela Profa. Dra. Alessandra Del Ré, conta com a participação pesquisadores graduandos e pós-graduandos do Programa de Linguística e Língua Portuguesa da FCLAr. Os trabalhos do GEALin estão ligados ao grupo NALingua (CNPq), em parceria com universidades francesas.
}

${ }^{4}$ Ver Bullio, 2008; Falasca, 2012; Silva, 2014.

Revista Leitura V.1 no 55 - jan/jun 2015 - Número temático: Estudos em perspectivas

dialógicas. Aprendizagem de língua estrangeira e argumentação em sala de aula: a perspectiva dialógica e discursiva em foco. Patrícia Falasca - p. 23 - 40. 
Eemeren e Grootendorst (1996). Em tal modelo de argumentação, busca-se, até certo ponto, conciliar a prática à teoria trazida pela Nova Retórica. Os trabalhos de Leitão (2011; 2008; 2007a; 2007b; 2003), especialmente mobilizados por nós nesta pesquisa, volta-se para a aplicação das noções trazidas nesses dois momentos dos estudos em argumentação para a sala de aula e sua participação no desenvolvimento do conhecimento epistêmico.

Neste contexto, faz-se importante lembrar que, na argumentação inserida nas aulas de línguas estrangeiras, muito mais importantes são a troca e a negociação por ela trazidas, que levam inevitavelmente ao diálogo entre os alunos, que o fato de realmente persuadir ou convencer o público. O engajar-se no ato argumentativo já proporciona para o aluno movimentos linguístico-discursivos que raramente aparecem na sala de aula em que a argumentação não está em foco, como buscaremos demonstrar neste trabalho.

Segundo Billig (1987), a argumentação é uma atividade que permeia nossa vida cotidiana, uma vez que a utilizamos nas mais diferentes situações, tanto em contextos públicos e interpessoais, como em contextos privados e intrapessoais (ao considerarmos, por exemplo, diálogos internos). Por isso, não é de se estranhar que tal atividade tenha despertado, nos últimos anos, crescente interesse por parte de professores e pesquisadores, em busca de compreensão do papel que ela poderia desempenhar justamente no contexto de ensino-aprendizagem, em suas mais variadas formas (LEITÃO, 2011, p.14).

Nesse contexto, encontramos nos trabalhos de Leitão (2011; 2009; 2008; 2007a; 2007b; 2003, 2000b) uma grande preocupação em compreender os movimentos cognitivo-discursivos presentes na argumentação e suas implicações benéficas para o processo de ensino-aprendizagem. Segundo a autora, ao engajar-se em argumentação, a busca do indivíduo para formular seus pontos de vista de forma clara e, ao mesmo tempo, de fundamentá-los, fazendo-os aceitáveis aos interlocutores, confere “à argumentação uma dimensão epistêmica - um mecanismo de produção/apropriação reflexiva do conhecimento, que torna a argumentação um recurso privilegiado em

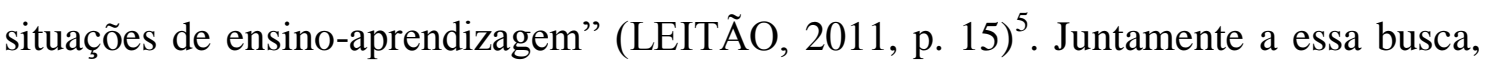
há a necessidade de o indivíduo estar disposto a considerar pontos de vistas contrários

\footnotetext{
${ }^{5}$ Para aprofundamento na proposta, ver também Leitão 2007a; 2007b; 2008, entre outros trabalhados da autora.

Revista Leitura V.1 no 55 - jan/jun 2015 - Número temático: Estudos em perspectivas dialógicas. Aprendizagem de língua estrangeira e argumentação em sala de aula: a perspectiva dialógica e discursiva em foco. Patrícia Falasca - p. 23 - 40.
} 
aos seus (contra-argumentos) - uma vez que a pertinência da argumentação está justamente em situações nas quais há pontos de vista divergentes sobre certo tema, ainda segundo Leitão (LEITÃO, 2011).

Assim compreendida, a argumentação:

Pode ser definida como uma atividade cognitiva (envolve raciocínios) de cunho social (dirige-se a um outro, presente, ou não, na situação imediata da argumentação) e de natureza discursiva (realiza-se na linguagem situada), em que se dá o confronto entre diferentes pontos de vista, com a finalidade de influenciar as concepções dos interlocutores acerca de um determinado tema. Assim compreendida, a argumentação se caracteriza por sua natureza dialógica, pois implica relação entre múltiplos enunciados/perspectivas que se respondem mutuamente (cf. BABKHTIN, 2000), e dialética, já que pressupõe a existência de oposição entre as perspectivas em questão. (VARGAS, G. C.; LEITÃO. S., 2011, p. 156-7)

Para as autoras, dentre as características da argumentação elencadas no excerto acima, seria sua perspectiva dialética (a oposição entre pontos de vista) o aspecto central em análises da dinâmica de aprendizagem em contextos argumentativos, uma vez que é justamente essa dimensão que permite uma discussão, possibilitando ao participantes um avanço em seu raciocínio (LEITÃO, 2011, p. 157).

É importante notar que essa forma de conceber a argumentação apenas se faz possível quando consideramos sujeitos concretos, sócio-historicamente situados, os quais se encontram em meio à cadeia de discursos presentes em sua sociedade (BAKHTIN/VOLOSHINOV, 1997) e que, justamente por isso, são capazes de, ao argumentar, considerar diferentes perspectivas relacionadas ao tema em discussão.

Nas palavras de Leitão,

[...] isso significa assumir o diálogo como uma perspectiva epistemológica particular, de acordo com a qual a linguagem e a ação humanas só podem ser investigadas e compreendidas contra o pano de fundo criado pelo ambiente sócio-histórico em que as mesmas emergem e pela linguagem e ação do outro (Bakhtin/Volochinov, 1995). Mesmo em situações de monólogo (palestras, textos escritos etc.), ou naquelas em que um indivíduo se engaja na argumentação apenas consigo mesmo (argumentação autodirigida), o diálogo é ainda o modelo que define a estrutura e o funcionamento da argumentação. Em tais situações, o diálogo se realiza pela presença de um oponente imaginário a quem a argumentação ultimamente se dirige e cuja voz (no sentido bakhtiniano do termo) traz para o contexto da argumentação um elemento de oposição (contra-argumentos, dúvidas, pontos de vista alternativos) indispensável à sua realização. A necessária existência de multiplicidade de perspectivas em relação a um tema é, portanto, elemento definidor do caráter dialógico da 
atividade argumentativa. Por sua vez, a presença de oposição no cerne destas perspectivas, confere à argumentação sua dimensão dialética. (LEITÃ̃, 2003, p. 3)

Assim, a argumentação, como definida por Leitão, prevê a oposição de pontos de vista como condição primária para sua existência. No entanto, segundo a autora, essa oposição não deve ser tomada apenas em seu sentido mais prototípico (quando consideramos, por exemplo, debates políticos ou questões judiciais), mas sim especialmente no contexto escolar - quando for possível mais de um entendimento sobre determinado tópico (curricular, no caso da escola) (LEITÃO, 2011, p. 18).

A dimensão dialógica da argumentação, ou seja, a possibilidade aberta pela oposição de ideias para a consideração de diversos pontos de vista, diversos discursos a respeito de um mesmo tema, confere-lhe um posicionamento especial, no qual é possível perceber a dinâmica existente entre os diálogos.

Com isso, a autora desenvolve um procedimento analítico que permite reconhecer e capturar os processos atravessados pelos indivíduos ao longo de situações argumentativas. Tal procedimento prevê uma unidade triádica de análise, composta por argumento, contra-argumento e resposta, sendo que:

O primeiro elemento, o argumento, é o elemento que permite identificar os pontos de vista defendidos por um falante numa discussão e as ideias com as quais os justifica. O segundo elemento, contra-argumento, consiste em qualquer ideia que possa 'pôr em xeque' o ponto de vista de um falante, seja este desafio trazido por um oponente presente na situação imediata da argumentação ou antecipado pelo próprio proponente de um argumento. $\mathrm{O}$ surgimento de objeções e desafios a posições defendidas é visto como condição pragmática indispensável para que um processo de revisão de pontos de vista se instale no discurso do proponente. Finalmente o terceiro elemento, a resposta, define-se como a reação imediata ou remota do proponente de um argumento a contra-argumentos levantados. (LEITÃO, 2003, p. 9) (grifos da autora)

Dentro dessa perspectiva, faz-se necessário notar que nem sempre é possível recuperar, no momento da análise, os três elementos que compõem a argumentação. Isso se deve ao fato de que nem sempre os três elementos se encontram enunciados no momento da interação. No entanto, apesar de não necessariamente ocorrer de forma clara e verbalizada, o movimento cognitivo que acompanharia o próprio ato de 
argumentar implicaria, necessariamente, nesses três elementos - verbalizados ou não (LEITÃO, 2007a).

Com isso, a autora propõe quatro possibilidades de resposta que podem ser desencadeadas pelo processo de argumentação (mas que não necessariamente, como dito, são explicitadas no momento da interação). A primeira possibilidade é a de que o contra-argumento seja diretamente rejeitado pelo argumentador, que preserva seu ponto de vista inicial, uma vez que considera o contra-argumento inaceitável, irrelevante. Uma segunda opção é também a rejeição do contra-argumento, considerado insuficiente e contando com uma justificativa do argumentador pela primazia de seu ponto de vista. Uma terceira possiblidade é a resposta ao contra-argumento, incluindo aspectos dele ao seu ponto de vista inicial, mas sem aceitá-lo totalmente (por, por exemplo, tomá-lo como insuficiente). Por fim, o quarto tipo de resposta implica na aceitação total do contra-argumento e, portanto, na retirada total do ponto de vista inicial (LEITÃO, 2011, p. 27-8).

É imprescindível notar que, mais importante que apresentar possibilidades de respostas a um contra-argumento, é justamente compreender os processos de construção de conhecimento presente em cada uma delas. Para Leitão,

Uma resposta à contra-argumentação só pode ser elaborada a partir de um processo em que o argumentador toma seu próprio argumento (suas ideias sobre o tema discutido) como objeto de reflexão e o avalia à luz da força que acredita ter a contra-argumentação. É exatamente esse processo que é visto aqui como essencial à (re)construção do conhecimento. (LEITÃO, 2011, p. 28)

Partindo de tais pressupostos teóricos, discutimos, então, de que forma e em que medida essas concepções podem contribuir para a aprendizagem de línguas estrangeiras.

\section{Argumentação na sala de aula de língua estrangeira}

Considerando o que foi até então exposto, propomos discutir de que forma e em que medida a inserção de atividades de caráter argumentativo na sala de aula de línguas estrangeiras pode contribuir para a entrada do aprendiz na língua que está aprendendo.

Para proceder a essa reflexão, tomamos como ponto de partida justamente a ideia defendida por Vargas e Leitão (2011, p.158) de que o confronto de perspectivas teria um importante papel tanto no desenvolvimento cognitivo, quanto social do aluno. 
Sendo propulsora mesmo desse desenvolvimento, a argumentação deveria, então, tomar um lugar privilegiado na sala de aula.

Apesar dos esforços para se reconhecer a importância da argumentação na educação, como apontamos acima, ainda pouco se discutiu mais especificamente sobre seu impacto na sala de aula de língua estrangeira, dentro da perspectiva adotada neste trabalho.

Tendo isso em vista e refletindo sobre as implicações desse processo de aprendizagem para o aprendiz, tanto no que diz respeito às suas expectativas enquanto falante, quanto às questões identitárias implicadas na aprendizagem de línguas ${ }^{6}$, defendemos que também neste contexto a argumentação possa ser de grande ajuda para que o aluno se insira na língua-alvo e torne-se nela sujeito, à medida que adentra seus discursos. Isso seria possível através da argumentação, da maneira como a consideramos neste trabalho, pois, além de seu caráter altamente dialógico, ela também impulsiona a (re)estruturação de pensamentos, processo que pode ser de grande valia para aqueles que se propõem a aprender uma nova língua - principalmente na fase adulta.

Assim, propomos observar e discutir dados advindos de um grupo de aprendizes de alemão como língua estrangeira, os quais são alunos do curso regular de Letras (Português-Alemão). Os participantes do grupo encontram-se, no momentos da gravação dos dados, entre o segundo e terceiro ano do curso, tendo já condições de se expressar em língua alemã, ainda que não muito fluentemente. Contamos, de início, com seis alunos, divididos em dois grupos. Para este trabalho, propomos uma breve análise de um trecho retirado da interação de apenas um dos grupos.

É importante lembrar que as atividades aqui discutidas foram desenvolvidas de forma paralela ao curso regular na Universidade e que os dados aqui discutidos fazem parte de uma coleta-piloto ${ }^{7}$, que contou com cerca de oito gravações em vídeo de encontros com cada um dos grupos. Cada encontro estendia-se entre sessenta e noventa minutos, nos quais os alunos eram levados a discutir temas específicos, apresentados no próximo item deste artigo.

\footnotetext{
${ }^{6}$ Para maiores informações sobre questões identitárias na aprendizagem de LE, em uma perspectiva dialógico-discursiva, ver Marchezan; Falasca; Bueno (2014), Falasca; Silva; Krause-Lemke (2014) Falasca, 2012 e Bueno, 2013.

${ }^{7}$ A coleta definitiva de dados para a pesquisa está programada para ocorrer na segunda metade de 2015. Revista Leitura V.1 no 55 - jan/jun 2015 - Número temático: Estudos em perspectivas dialógicas. Aprendizagem de língua estrangeira e argumentação em sala de aula: a perspectiva dialógica e discursiva em foco. Patrícia Falasca - p. $23-40$.
} 
Nossa principal hipótese de trabalho é a de que as atividades essencialmente argumentativas abrem para o aluno a possibilidade de inserir-se na língua alvo, à medida que formulam seus argumentos, contra-argumentos e respostas nessa língua e buscam defender seus pontos de vista e fazer-se entender (e, muitas vezes, aceitar) pelos colegas. A oportunidade de negociação de significados aberta também por essas atividades e o engajamento dos alunos na defesa de seus pontos de vista são, a nosso ver, de extrema valia para que, a cada discussão, os alunos sintam-se também sujeitos dessa nova língua e passem, cada vez mais, a enunciar na língua que aprendem.

\section{Um projeto-piloto e suas possibilidades de análises}

O dado que trazemos para ilustrar o que até então foi apresentado faz parte de uma coleta realizada de modo experimental, de forma a verificar a abertura dos alunos, a disponibilidade de horários e sua frequência aos encontros planejados para a coleta do corpus da pesquisa. Mesmo sendo uma coleta preliminar, conseguimos reconhecer, em diversos momentos, os impactos positivos que a inserção de atividades argumentativas na sala de aula de língua estrangeira pode trazer para os alunos.

Durante os encontros, foram propostos temas a serem discutidos pelos alunos. Tais temas não continham em si grandes dificuldades de interpretação, pois nosso intuito não era levar o aluno a grandes conclusões sobre temas em si problemáticos, mas, sim, fazer com que eles expressassem e negociassem seus pontos de vista sobre temas relativamente simples de serem discutidos.

Assim, foram propostos os temas "homens $x$ mulheres", "família”, "escola”, os quais trazem a possibilidade de gerar pontos de vista opositivos, para que, a partir de diferentes posicionamentos, os alunos sejam capazes de se engajar em argumentação (LEITÃO, 2011).

Apresentamos aqui um recorte das discussões realizadas no terceiro encontro de um dos grupos com os quais trabalhamos. O tema em questão era "homens $x$ mulheres" e os alunos haviam ouvido, lido e trabalhado com o vocabulário da canção "Der kleine Unterschied", de Annett Louisan, e estavam discutindo a validade dos clichês que apareciam ao longo da música - todos relacionados ao tema proposto.

A questão que eles se colocaram, a partir da música, foi: as mulheres querem sempre "prender" os homens - ideia reconhecida como clichê pelos alunos -, ou, na verdade, os homens sempre querem "prender" as mulheres? 
Daí a seguinte discussão ${ }^{8}$ :

$\mathbf{1}$ E: tem um clichê também sobre a
mulher / Die Frau immer hat / hat? Die
Mann einzusperren.
$\mathbf{2}$ P: die Frau hat immer versucht
$\mathbf{3}$ L: nicht immer
$\mathbf{4}$ E: es ist ein Klischee
$\mathbf{5}$ P: (dirigindo-se para L) aber du kannst
dagegen

6 E: ah, não sei / Die Frauen / die immer 7 A: ich bin nicht dafür. Eu entendi o que você quis dizer

8 L: eu também.

9 P: die sind beide nicht dafür

$10 \mathrm{E}$ : que a mulher sempre prende o homem?

(...)

11 A: ich bin nicht einverstanden é:

12 E: você não entendeu?

13 A: não. Eu não estou de acordo.

Meiner Meinung nach / daí eu tenho que colocar o verbo, né? / Só que eu não / versuchen die Männer immer, dass / você tem que por "o que" / Tá certo o dass?

14 P: ich brauche das nicht. Meiner Meinung nach, versuchen die Männer immer

15 A: é que a frase que eu bolei não cabe no "meiner Meinung nach"

16 P: okay, dann mach das anders. So / ich persönlich denke

17 A: Ah okay / Boa / Ich persönlich denke, dass die Männer / é: versuchen é: / die Frauen einzusperren, denn die / tá certo?

18 P: Die Männer /ja

19 E: então você tá falando que é o contrário?

20 A: é. Denn die wollen nicht, dass die Frauen / é: ausgehen / é: allein allein ausgehen

21 E: hum (faz gesto de concordância com a cabeça)

22 A: sie sind immer / eu não sei como que é ciumento

23 P: eifersüchtig
1 E: tem um clichê também sobre a mulher / a mulher sempre prender o homem

2 P: a mulher sempre tentou

3 L: nem sempre

4 E: é um clichê

5 P: (para L) mas você pode ir contra

6 E: ah, não sei / as mulheres / elas sempre

7 A: eu não concordo. Eu entendi o que você quis dizer

8 L: eu também

9 P: os dois não concordam

$10 \mathrm{E}$ : que a mulher sempre prende o homem?

(...)

11 A: eu não concordo é:

12 E: você não entendeu?

13 A: não. Eu não estou de acordo. $\mathrm{Na}$ minha opinião / daí eu tenho que colocar o verbo, né? / Só que eu não / os homens sempre tentam, que / você tem que por "o que" / Tá certo o dass?

14 P: eu não preciso. Na minha opinião, os homens sempre tentam

15 A: é que a frase que eu bolei não cabe no "na minha opinião"

16 P: okay, então faça diferente. Assim / eu pessoalmente acho

17 A: ah okay / Boa / eu pessoalmente acho que os homens / é: tentam é: / prender as mulheres, pois eles / tá certo?

18 P: os homens / sim

19 E: então você tá falando que é o contrário?

20 A: é. Pois eles não querem que as mulheres / é: saiam / é saiam sozinhas sozinhas

21 E: hum (faz gesto de concordância com a cabeça)

22 A: eles são sempre eu não sei como que é ciumento

23 P: eifersüchtig

\footnotetext{
${ }^{8} \mathrm{Na}$ transcrição, $E$, $A$ e $L$ são os alunos ( $E$ e $L$ do sexo feminino, $A$ do sexo masculino). $P$, a professora. Tradução nossa.

Revista Leitura V.1 no 55 - jan/jun 2015 - Número temático: Estudos em perspectivas
} dialógicas. Aprendizagem de língua estrangeira e argumentação em sala de aula: a perspectiva dialógica e discursiva em foco. Patrícia Falasca - p. $23-40$. 
24 A: sie sind immer mehr eifersüchtig 25 E: eu acho / ich finde, dass / não / peraí. Ich bin mir nicht ganz sicher. Ich finde, dass (incompreensível) die einzusperren sind für beiden. Für beiden. Die Frau kann versucht die Mann einzusperren und der Mann ah, ah, okay. Und der Mann kann versuchen, der Frau einzusperren. Hum. Zum Beispiel. Zum Beispiel / peraí / das ist nicht / hum / certo?

26 L: richtig.

27 E: das nicht richtig / du musst /du musst?

28 P: (faz sinal afirmativo com a cabeça) 29 E: du musst / hum / mit mir geb / mit mir bleiben. Ich finde, das ist für beide. 30 A: ja, ich muss zugeben. Essa eu sempre quis usar (risos). Ich muss zugeben, dass die beide / die beide das machen. Aber die Männer costumam / como fala costumar?

31 E: ist mehr Cliché? Du findest? Findest du / die

(...)

32 E: für mich die Frauen versuchen die Männer einzusperren klingt mehr als Cliché. Für mich.

33 P: du musst zugeben, dass...

34 A: ja, ich muss zugeben, dass die beiden das machen. Einzusperren.

Einsperren versuchen. Aber die Männer zum Beispiel sagen é: sagen immer é: du é: como eu falo

35 E: (risos)

36 A: du musst du sollst nicht das Klei / die Kleidung / dieses Kleid / diese Kleidung

37 L: diese Kleidung

38 A: anziehen / antragen / Mit diese Kleidung ausgehen. É mais sufocante.

39 E: (pensativa) ja

40 A: oder mit diesem Freund / Freund / unter / reden

(...)

$41 \mathrm{E}$ : Ich habe keine Erfahrung mit der Gegensituation aber du hast ein Punkt.

42 A: (risos)

43 P: gut. Sehr schön.
24 A: eles são sempre mais ciumentos 25 E: eu acho / eu acho que / não / peraí. Eu não tenho certeza. Eu acho que (incompreensível) o prender é para os dois. Para os dois

A mulher pode tentar prender o homem e o homem ah, ah, okay. E o homem pode tentar prender a mulher. Hum. Por exemplo / peraí / isso não é / hum / certo?

26 L: richtig

27 E: isso não é certo / você tem / você tem ?

28 P: (faz sinal afirmativo com a cabeça) 29 E: você tem / hum / comigo / ficar comigo. Eu acho que é para os dois 30 A: sim, eu tenho que admitir. Essa eu sempre quis usar (risos). Eu devo admitir que ambos / ambos fazem isso. Mas os homens costumam / como fala costumar?

31 E: é mais clichê? Você acha? Você acha que

32 E: para mim soa mais clichê que as mulheres querem prender os homens. Para mim

33 P: você tem que admitir que...

34 A: sim, eu tenho que admitir que ambos fazem isso. Mas os homens dizem, por exemplo é: sempre dizem é: você é: como eu falo

\section{E: (risos)}

36 A: você não deve você não pode a rou / a roupa / esse vestido / essa roupa

$37 \mathrm{~L}$ : essa roupa

38 A: vestir / usar / sair com essa roupa. É mais sufocante

39 E: (pensativa) sim

40 A: ou com esse amigo / amigo / conv / falar

(...)

$41 \mathrm{E}$ : eu não tenho nenhuma experiência com a situação contrária, mas você tem um ponto.

42 A: (risos)

43 P: bom. Muito legal.

Revista Leitura V.1 no 55 - jan/jun 2015 - Número temático: Estudos em perspectivas dialógica e discursiva em foco. Patrícia Falasca - p. $23-40$. 
Nesse trecho, notamos claramente os movimentos de argumento - contraargumento e resposta, tríade analítica proposta por Leitão ao longo de seus trabalhos para compreender a argumentação.

Entre os turnos 1 a 10, $E$ expõe seu argumento (as mulheres sempre tentam prender o homem). Imediatamente (turnos 3 e 7), $L$ e $A$ posicionam-se contra tal argumento e, a partir de então, desenvolve-se a discussão, mais centrada entre $A$ e $E$. Entre os turnos 13 e 24, $A$ apresenta o seu contra-argumento: os homens seriam mais ciumentos e tentariam prender as mulheres, mais do que as mulheres o fariam.

A aluna $E$, por sua vez, no turno 21, faz um gesto de concordância com o contra -argumento apresentado pelo colega, mas, ao mesmo tempo, dá uma resposta, não retirando o seu ponto de vista inicial, mas adicionando a ela, ainda que parcialmente, a ideia do colega: ambos os sexos fariam a tentativa de prender um ao outro (turnos 25 29). Esse movimento de repensar seu ponto de vista inicial nos remete ao terceiro tipo de resposta proposto por Leitão (2011), no qual o argumentador não retira seu ponto de vista inicial frente ao contra-argumento, mas inclui aspectos dele em sua argumentação.

Assim, nos turnos seguintes, $A$ busca reafirmar seu ponto de vista, ao passo que $E$, mesmo que ainda defenda seu posicionamento inicial, admite que o colega tem razão e altera, de maneira parcial, sua colocação.

Especialmente interessante nesse trecho é o trabalho com a língua realizado pelos alunos ao longo da discussão. Há um esforço, por parte de $A$ e $E$, especialmente, em utilizar-se de expressões típicas da língua alemã em contextos de argumentação (como em: meiner Meinung nach; ich persönlich finde; ich muss zugeben, dass...; ich bin mir nicht ganz sicher, ich finde, dass...) e, conforme colocam em uso tais expressões, vão esforçando-se para se fazer entender e para defender seu ponto de vista de forma clara. Suas ideias passam a ser colocadas na língua aprendida e, muitas vezes, é necessário adaptar o pensamento inicial, recomeçar a expressar o pensamento, para que ele seja compreendido pelos colegas (como, por exemplo, faz $A$ entre os turnos 13 e 15). Esse pensar e repensar passa, necessariamente, pela língua alemã e os alunos vão, pouco a pouco, lidando com ela e suas estruturas (como, por exemplo, o correto posicionamento do verbo, preocupação de $A$ no turno 13). 
Há também, ao longo da discussão, negociações de significados de palavras desconhecidas pelos alunos. Às vezes, a professora colabora, dizendo a palavra (turnos 22 - 24 - a palavra ciumento/ eifersüchtig). Outras vezes, eles negociam entre si a melhor possibilidade para o caso (turnos 25 a 27- a palavra certo/ richtig).

Ao longo das discussões, percebemos a forma como os alunos se posicionam frente aos diálogos presentes na sociedade e como, em suas palavras e em seus próprios enunciados, criam elos na cadeia de comunicação. Responder e gerar outras respostas faz-se a base para a compreensão da argumentação, como a consideramos aqui estreitamente ligada à ideia do dialogismo bakhtiniano.

\section{Conclusão - o que a argumentação pode trazer para a sala de aula de língua estrangeira?}

Ao longo deste artigo, buscamos elucidar os desdobramentos da perspectiva bakhtiniana de estudos, fazendo uma reflexão sobre sua utilização na área de ensinoaprendizagem de línguas e, principalmente, suas implicações para a compreensão da argumentação, da forma como a entendemos neste trabalho.

Com a análise proposta para um recorte dos dados preliminares da pesquisa, pudemos observar como a argumentação se desenvolve na sala de aula e de que forma os alunos se engajam nas atividades argumentativas.

Não podemos deixar de notar o quanto a participação da professora é reduzida ao longo do debate, dando aos alunos mais espaço para que exponham, refutem, debatam e defendam suas ideias. Isso gera, ao longo das aulas, um ambiente bastante descontraído, de forma a também incentivar a participação dos alunos na argumentação.

É interessante perceber o quanto os alunos realmente se envolvem na discussão, ansiando por propor ou defender seus pontos de vista e, muitas vezes (como vimos no exemplo aqui discutido), reformular suas ideias iniciais, ainda que parcialmente.

O trabalho com a língua realizado pelos alunos, em conjunto com o professor, demonstra que nossa hipótese de trabalho faz-se pertinente, uma vez que, através da argumentação, os alunos esforçam-se para utilizar a língua alemã, para se fazer entender pelos demais, para fazer uso de expressões que não surgem facilmente em um ambiente de sala de aula que não disponha de atividades argumentativas. Portanto, defendemos o ponto de vista de que, nessas atividades, os alunos podem, cada vez mais, inserir-se na 
língua que estão aprendendo, à medida que defendem seus pontos de vista e discutem com os demais aspectos de conteúdo ou de forma da língua.

A oportunidade de fala gerada pelas atividades de cunho argumentativo abrem para os alunos possibilidades de, realemente, sentirem-se sujeitos na língua em que estão enunciando, ainda que a sua língua materna esteja sempre presente e faça parte também das discussões.

Portanto, vemos nas atividades que envolvem argumentação na sala de aula grandes aliadas para compor o planejamento escolar, permitindo aos alunos novos olhares e oportunidades dentro da língua estrangeira.

\section{Agradecimentos}

À CAPES, por possibilitar esta pesquisa.

\section{Referências}

BAKHTIN, M. Estética da criação verbal. São Paulo: Martins Fontes, 2006.

BAKHTIN, M.; VOLOSHINOV, V. N. Marxismo e filosofia da linguagem. São Paulo: Huitec, 1997.

BAKHTIN, M. The dialogic imagination (M. Holquist, Ed., C. Emerson \& M.

Holquist, Trans.). Austin: University of Texas Press, 1981.

BAKHTIN, M; VOLOSHINOV, V.N. Discurso na vida e discurso na arte. (1926). Trad. Inédita de Cristóvão Tezza do artigo "Discourse in Life and Discourse in Art.", publicado como apêndice in: Voloshinov, V.N. Freudianism: a marxist critique. New York: Academic Press, 1976.

BILLIG, M. Arguing and thinking: A rethorical approach to social psychology. Cambridge, Inglaterra: Cambridge University Press, 1987.

BULLIO, P. C. Mediação cultural no processo de aprendizagem de língua estrangeira. Dissertação de mestrado - Universidade Estadual Paulista (UNESP) - Araraquara, 2008.

FALASCA, P.; SILVA, A. O.; KRAUSE-LEMKE, C.. Aquisição/aprendizagem de língua estrangeira. In: DEL RÉ, A.; DE PAULA, L.; MENDONÇA, M. C. (Orgs.). Explorando o discurso da criança. 1.ed. São Paulo: Contexto, 2014, v. 1, p. 145-162.

FALASCA, P. Aquisição/aprendizagem de LE: subjetividade e deslocamentos identitários. Dissertação de mestrado - Universidade Estadual Paulista (UNESP) - Araraquara, 2012.

FRANÇOIS, F. O que nos indica a "linguagem da criança": algumas considerações sobre a "linguagem". In: DEL RÉ, A. Aquisição da linguagem: uma abordagem psicolinguística. São Paulo: Contexto, 2006.

Práticas do oral. Trad. de Lélia Erbolato Melo. São Paulo: Pró-Fono, 1996.

Revista Leitura V.1 no 55 - jan/jun 2015 - Número temático: Estudos em perspectivas dialógicas. Aprendizagem de língua estrangeira e argumentação em sala de aula: a perspectiva dialógica e discursiva em foco. Patrícia Falasca - p. $23-40$. 
Langage et pensée: dialogue et mouvement discursif chez Vygotsky et Bahktine. In: Enfance 1-2. Paris : PUF, 1989.

HALL, J. K.(Ed.). Dialog with Bakhtin on second and foreign language learning: new perspectives. New Jersey: Lawrence Erlbaum Associates, 2005.

KRAMSCH, Claire. The multilingual subject. Oxford University Press: New York, 2009.

Language and culture. Oxford University Press: New York, 1998.

Context and culture in language teaching. Oxford University Press: New York, 1993.

LEITÃO, S. O lugar da argumentação na construção do conhecimento em sala de aula. Em: LEITÃO, S.; DAMIANOVIC, M. C. (orgs.). Argumentação na escola: O conhecimento em construção. Campinas: Pontes Editores, 2011.

. Auto-argumentação na linguagem da criança: momento crítico na gênese do pensamento reflexivo. DEL RE, A.; FERNANDES, S.D. (orgs.) A linguagem da criança: sentido, corpo e discurso. São Paulo: Cultura Acadêmica, Série Trilhas Linguísticas 15, 2008, p. $35-60$.

Processos de construção do conhecimento: a argumentação em foco. In: ProPosições, Campinas, v. 18, n.3 [54], p. 75-92, set./dez. 2007a.

. Argumentação e desenvolvimento do pensamento reflexivo. In: Psicologia: Reflexão e Crítica, 20(3), 454-462, 2007b. Disponível em: http://www.scielo.br/pdf/prc/v20n3/a13v20n3.pdf. Acesso: janeiro de 2015.

. Argumentação como processo de construção do conhecimento. 2003.

MARCHENKOVA, L. A. Interpreting dialog: Bakhtin's theory and second language learning. Dissertation. Ohio State University, 2005.

MARCHEZAN, R. C.; FALASCA, P.; BUENO, R. G. Aquisição/Aprendizagem de língua estrangeira e as contribuições bakhtinianas. In: Del Ré, A.; De Paula, L.; Mendonça, M. C. (Orgs.). A linguagem da criança: um olhar bakhtiniano. 1ed.São Paulo: Editora Contexto, 2014, v. 1, p. 95-111.

MOLON, N. D.; VIANNA, R. O Círculo de Bakhtin e a Linguística Aplicada. In: Bakhtiniana, São Paulo, 7 (2): 142-165, Jul./Dec. 2012.

PERELMAN, C.; OLBRECHTS-TYTECA, L. Tratado da argumentação: a nova retórica. São Paulo: Martins Fontes, 2000.

SALAZAR ORVIG, A. (et al.) Dialogical beginnings of anaphora: The use of third person pronouns before the age of 3. In: Journal of Pragmatics 42, 2010a, p. 1842-1865.

SALAZAR ORVIG, A. Dialogical factors in toddlers' use of clitic pronouns. In: First Language 30(3-4), 2010b, p. 375-402.

Les mouvements du discours: style, référence et dialogue dans des entretiens cliniques. Paris: Harmattan, 1999.

Revista Leitura V.1 no 55 - jan/jun 2015 - Número temático: Estudos em perspectivas dialógicas. Aprendizagem de língua estrangeira e argumentação em sala de aula: a perspectiva dialógica e discursiva em foco. Patrícia Falasca - p. $23-40$. 
SILVA, A. O. Aquisição/aprendizagem de LE na infância: a produção de enunciados em inglês por crianças. Dissertação de mestrado - Universidade Estadual Paulista (UNESP) - Araraquara, 2014.

VAN EEMEREN, F. H. (et al.). Fundamentals of argumentation theory: a handbook of historical backgrounds and contemporary developments. New Jersey: Erlbaum Associates, 1996.

VARGAS, G. C.; LEITÃO, S. Ações epistêmica na argumentação entre pares em sala de aula. In: LEITÃO, S.; DAMIANOVIC, M. C. (orgs.). Argumentação na escola: O conhecimento em construção. Campinas: Pontes Editores, 2011, p. 153-182. 